\title{
ĐÁNH GIÁ TÍNH BỀN VỬNG ĐỚI BỜ - THÍ ĐIỂM TẠI HUYỆN PHÙ CÁT, TỈNH BİNH ĐỊNH
}

\author{
Võ Thanh Tịnh ${ }^{1 *}$, Chế Đình Lý ${ }^{1}$, Lương Văn Thanh ${ }^{2}$ \\ ${ }^{1}$ Viện Môi trường và Tài nguyên-Đại học Quốc gia thành phố Hồ Chí Minh \\ ${ }^{2}$ Viện Kỹ thuật Biển-Viện Khoa học Thủy lợi Việt Nam \\ "E-mail: tinhmtbd@gmail.com
}

Ngày nhận bài: 18-7-2013

\begin{abstract}
TÓM TÁT: Dựa vào các bộ chỉ thị đánh giá tính bền vũng đã công bố, các tác giả nghiên cứu, thiết lập bộ chỉ thị với 6 nhóm chủ đề và 38 chỉ thị và các bậc bền vũng (5 bậc) cho các yếu tố phuc vu công tác đánh giá tính bền vũng đới bờ, thi điểm tại huyện Phù Cát, tỉnh Bình Định. Nghiên cứu này đãa áp dưng phuoong pháp phân tích tiến trình cấp bậc (AHP) để thiết lập tập hợp trọng số cho tùng chủ đề và tùng chỉ thị. Sau khi tính toán kết quả đánh giá với phuoong pháp đánh giá toàn diện

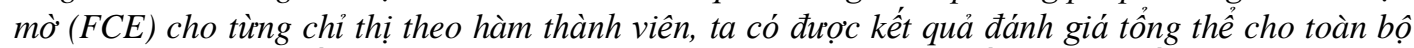
huyện Phù Cát. Từ kết quả tính toán và đánh giá các tiêu chí cho thấy mức độ bền vững của huyện Phù Cát ở mức trung bình.
\end{abstract}

Tù̀ khóa: Tính bền vũng, đới bò̀, huyện Phù Cát.

\section{MỞ ĐẦU}

Phù Cát là một trong năm huyện, thành phố ven biển của tỉnh Bình Định với diện tích $679 \mathrm{~km}^{2}$ và dân số khoảng 194.000 người (2012). Nằm ở khu vực ven biển với đường bờ biển dài gần $40 \mathrm{~km}$ và sở hữu đầm Đề $\mathrm{Gi}$ - một trong những đầm phá lớn của nước ta, khu vực ven biển huyện Phù Cát có vai trò quan trọng trong quá trình phát triển kinh tế-xã hội của tỉnh Bình Định. Diện tích nuôi trồng thủy sản hiện nay là 391 ha. Trong số này có 176 ha mặt nước lợ với 47 ha nuôi tôm thâm canh, bán thâm canh và 129 ha nuôi theo phương thức quảng canh cải tiến hỗn hợp các loại thủy sản. Tổng sản lượng khai thác và nuôi trồng thủy sản trong năm 2012 đạt 35.000 tấn. Trong đó, sản lượng khai thác chiếm $94 \%$, sản lượng nuôi trồng chiếm 6\%. Toàn huyện có 1.207 tàu thuyền đánh bắt thủy sản [1], trong đó phần lớn là tàu thuyền đã sử dụng lâu năm, máy móc thiết bị lạc hậu, khả năng chịu đựng sự tác động của sóng gió yếu nên rất dễ xảy ra sự cố trong mùa mưa, bão.
Theo số liệu thống kê của Ban chỉ huy Phòng chống lụt bão huyện năm 2012, Phù Cát có 1.448 hộ dân với 6.961 nhân khẩu thuộc các xã: Cát Nhơn, Cát Hưng, Cát Thắng, Cát Minh, Cát Khánh, Cát Thành, Cát Hải, Cát Tiến, Cát Chánh, Cát Tường, Cát Tân ở vùng hạ lưu sông Côn, sông La Tinh, ven đầm Đề Gi, ven biển thường bị đe dọa bởi triều cường, ngập lụt và sạt lở đất, không đảm bảo an toàn mối khi xảy ra mưa lũ lớn. Ngoài ra, các đoạn đê sông Côn thuộc địa bàn thôn Đại Lợi (Cát Nhơn), Chánh Lý (Cát Tường) và đoạn đê sông La Tinh thuộc địa bàn thôn Thái Bình (Cát Tài) đã bị sạt lở nặng, vỡ đê nếu xảy ra bão, lũ.

\section{TÀI LIỆ VÀ PHƯƠNG PHÁP NGHIÊN CúU}

Dựa vào phương pháp đánh giá toàn diện mờ (FCE) để phân tích, lựa chọn các công trình xanh tại Thâm Quyến, Trung Quốc của Sun et al. (2006) [4], tác giả thiết lập phương pháp đánh giá tính bền vững huyện Phù Cát, các bước thực hiện như sau: 
Bảng 1. Bộ chỉ thị đánh giá tính bền vững huyện Phù Cát

\begin{tabular}{|c|c|c|c|c|}
\hline NHÓM & CHİ TH! & $\begin{array}{l}\text { KÝ } \\
\text { HIẸU }\end{array}$ & $\begin{array}{l}\text { ĐớN V! } \\
\text { TíNH }\end{array}$ & $\begin{array}{l}\text { SÓ LIẸU THÓNG } \\
\text { KÊ NĂM } 2012 \\
\end{array}$ \\
\hline \multirow{8}{*}{$\begin{array}{l}\text { 1. Phát triển } \\
\text { KT-XH gắn } \\
\text { với vai trò } \\
\text { ngành thủy } \\
\text { sản }\end{array}$} & 1.1. Thu nhập bình quân đầu người/tháng & KT1.1 & Nghìn đồng & $3.290,0$ \\
\hline & 1.2.Vốn sản xuất kinh doanh của các doanh nghiệp & $\mathrm{KT} 1.2$ & Tỷ đồng & 841,0 \\
\hline & 1.3.Tỉ lệ đầu tư trong GDP & KT1.3 & $\%$ & 37,9 \\
\hline & 1.4. Giá trị sản xuất công nghiệp & KT1.4 & Tỷ đồng & 197,9 \\
\hline & 1.5. Giá trị sản xuất ngành nông nghiệp & KT1.5 & Tỷ đồng & 460,7 \\
\hline & 1.6. Sản lượng thủy sản nuôi trồng & KT1.6 & Tấn/năm & 440,0 \\
\hline & 1.7. Sản lượng khai thác cá biển & KT1.7 & Tấn/năm & $18.716,0$ \\
\hline & 2.1. Tỷ lệ xã, phường có bác sỹ & $\mathrm{XH} 2.1$ & $\%$ & 100,0 \\
\hline \multirow{5}{*}{$\begin{array}{l}\text { 2. Dân cư, y } \\
\text { tế, giáo dục }\end{array}$} & 2.2. Tỷ lệ học sinh đỗ tốt nghiệp THPT & $\mathrm{XH} 2.2$ & $\%$ & 96,1 \\
\hline & 2.3.Mật độ dân số & $\mathrm{XH} 2.3$ & Người/km² & 277,1 \\
\hline & 2.4. Tỷ lệ gia tăng dân số & $\mathrm{XH} 2.4$ & $\% 0$ & 9,1 \\
\hline & 2.5.Tỷ lệ giới tính nữ & $\mathrm{XH} 2.5$ & $\%$ & 51,1 \\
\hline & 2.6. Tỷ lệ dân cư ở đô thị & $\mathrm{XH} 2.6$ & $\%$ & 5,6 \\
\hline \multirow{6}{*}{$\begin{array}{l}\text { 3. Sinh hoạt, } \\
\text { văn hóa }\end{array}$} & 3.1.Tỷ lệ hộ sử dụng điện & VH3.1 & $\%$ & 99,4 \\
\hline & 3.2.Tỷ lệ hộ dùng nước sạch trong sinh hoạt & VH3.2 & $\%$ & 54,0 \\
\hline & 3.3.Số hộ có nhà vệ sinh phù hợp & VH3.3 & $\%$ & 34,5 \\
\hline & 3.4. Thắng cảnh du lịch & VH3.4 & Đơn vị & 1,0 \\
\hline & 3.5. Số cơ sở lưu trú (khách sạn) & VH3.5 & Cơ sở & 1,0 \\
\hline & 3.6. Số thuê bao điện thoại /100 dân & VH3.6 & Thuê bao & 76,0 \\
\hline \multirow{6}{*}{$\begin{array}{l}\text { 4. Môi } \\
\text { trường, hệ } \\
\text { sinh thái }\end{array}$} & $\begin{array}{l}\text { 4.1. Hàm lượng COD trong nước mặt lục địa tại các } \\
\text { cứa sông chính }\end{array}$ & MT4.1 & $\mathrm{Mg} / \mathrm{l}$ & 16,0 \\
\hline & 4.2. Hàm lượng SS trong nước biển ven bờ & MT4.3 & $\mathrm{Mg} / \mathrm{l}$ & 0,8 \\
\hline & 4.3. Hàm lượng CO trong không khí & MT4.4 & $\mu \mathrm{g} / \mathrm{m} 3$ & 3,1 \\
\hline & 4.4. Diện tích rừng ngập mặn & MT4.5 & ha & 56 \\
\hline & 4.5. Diện tích thảm cỏ biển & MT4.6 & ha & 50 \\
\hline & 4.6. Diện tích đầm phá & & ha & 750 \\
\hline \multirow{6}{*}{$\begin{array}{l}\text { 5. Khí hậu và } \\
\text { tác động của } \\
\text { BĐKH }\end{array}$} & 5.1.Nhiệt độ & KH5.1 & ${ }^{0} \mathrm{C}$ & 27,4 \\
\hline & 5.2. Lượng mưa & KH5.2 & $\mathrm{mm}$ & $2.684,0$ \\
\hline & 5.3.Tần suất các các cơn bão, lũ, hạn hán & KH5.3 & cơn & 3,0 \\
\hline & 5.4. Số người chết do thiên tai & KH5.4 & Người & 2,0 \\
\hline & 5.5.Nhà cửa bị cuốn trôi, sập & KH5.5 & Căn & 5,0 \\
\hline & 5.6. Thiệt hại về tài sản do các thảm hoạ thiên tai & KH5.6 & Tỷ đồng & 60,0 \\
\hline \multirow{7}{*}{$\begin{array}{l}\text { 6. Cơ chế, } \\
\text { chính sách } \\
\text { đầu tư phát } \\
\text { triển và kế } \\
\text { hoạch ứng } \\
\text { phó với biến } \\
\text { đổi khí hậu }\end{array}$} & 6.1.Chất thải rắn sinh hoạt được thu gom, xử lý & CS6.1 & $\%$ & 35,0 \\
\hline & 6.2.Các hệ sinh thái biển, ven biển được nghiên cứu & CS6.2 & Khu & 1,0 \\
\hline & 6.3. Rừng trồng mới nhằm ứng phó với $\mathrm{BĐKH}$ & CS6.3 & ha & 469,0 \\
\hline & 6.4. Kinh phí sự nghiệp môi trường & CS6.4 & Triệu đồng & $1.900,0$ \\
\hline & 6.5. Cơ cấu vốn đầu tư của ngành thủy sản & CS6.5 & $\%$ & 3,0 \\
\hline & $\begin{array}{l}\text { 6.6. Số dự án quản lý tổng hợp đới bờ, ứng phó } \\
\text { BĐKH }\end{array}$ & CS6.6 & Dự án & 1,0 \\
\hline & 6.7.Hỗ trợ vốn ngư dân đánh bắt xa bờ & CS6.7 & Tỷ đồng & 0,0 \\
\hline
\end{tabular}


(1) Thiết lập ma trận đánh giá $\mathrm{U}: \mathrm{U}=\left(\mathrm{U}_{1}\right.$, $\left.\mathrm{U}_{2}, \mathrm{U}_{3}, \ldots \mathrm{U}_{6}\right)=$ nhóm 1, nhóm 2, nhóm 3, nhóm 4, nhóm 5, nhóm 6\}.

Mỗi nhóm chủ đề $\left(\mathrm{U}_{\mathrm{i}}\right)$ bao gồm tập hợp yếu tố thứ cấp $\mathrm{U}_{\mathrm{i}}=\left(\mathrm{U}_{\mathrm{i} 1}, \mathrm{U}_{\mathrm{i} 2}, \mathrm{U}_{\mathrm{i} 3}, \ldots \mathrm{U}_{\mathrm{in}}\right)$, trong đó: $\mathrm{I}=1,2,3, \ldots, 6$ là số chỉ thị cơ bản khác nhau có trong một nhóm chủ đề.

(2) Xây dựng chuẩn đánh giá ma trận $\mathrm{V}$ $=\left\{\mathrm{V}_{1}, \mathrm{~V}_{2}, \mathrm{~V}_{3}, \mathrm{~V}_{4}, \mathrm{~V}_{5}\right\}=\{$ không bền vững $(\mathrm{I})$, kém bền vững (II), bền vững trung bình (III), khá bền vững (IV), bền vững $(\mathrm{V})$ \}.

(3) Thiết lập tập hợp trọng số của mỗi yếu tố trong tập hợp:

$$
\mathrm{UA}=\left(\mathrm{A}_{1}, \mathrm{~A}_{2}, \ldots \ldots \mathrm{A}_{6}\right) \mathrm{A}_{\mathrm{i}}>0, \sum_{1}^{6} \mathrm{~A}_{\mathrm{i}}
$$

Tập hợp trọng số của

$$
\mathrm{U}_{\mathrm{i}}=(\mathrm{i}=1,2, \ldots \ldots .6)
$$

là:

$$
\begin{gathered}
\mathrm{A}_{\mathrm{i}}=\left(\mathrm{a}_{1}, \mathrm{a}_{2}, \ldots \ldots \mathrm{a}_{\mathrm{n}}\right) \\
\mathrm{a}_{\mathrm{i}}>0, \quad \sum_{1}^{6} \mathrm{a}_{\mathrm{i}}=1
\end{gathered}
$$

n: là số chỉ thị khác nhau có trong một chủ đề.

Các trọng số trong nghiên cứu được tính theo phương pháp phân tích tiến trình thứ bậc (AHP) của Saaty (2000) [3]. Phương pháp AHP thực hiện so sánh từng cặp tiêu chí để xác định tầm quan trọng tương đối của một tiêu chí đối với tiêu chí khác.

(4) Đánh giá từng yếu tố riêng rẻ theo thuật toán mờ.

Ma trận đánh giá $\mathrm{R}_{\mathrm{i}}=\left(\mathrm{r}_{\mathrm{i}}\right)_{n x m}$ có thể tính được để thực hiện đánh giá mờ từng yếu tố riêng rẻ trong tập hợp $U$ được phân bậc theo các chủ đề $\mathrm{U}_{\mathrm{i}}$. Trong đó $\mathrm{R}_{\mathrm{ij}}(1,2,3 \ldots 5,6)$ diễn đạt mức độ thành viên của chủ đề $\mathrm{j}$ đối với "bậc đánh giá" Vi. Và ma trận các lớp tiếp theo có thể tính được cùng phương pháp.
(5) Kết quả đánh giá toàn diện theo thuật toán mờ.

Vectơ đánh giá toàn diện của các chỉ số từng chỉ thị trong hệ thống được tính theo công thức:

$$
\mathrm{A}_{\mathrm{i}}=\mathrm{B}_{\mathrm{i}} \bullet \mathrm{R}_{\mathrm{i}} .
$$

Ma trận đánh giá toàn diện mờ trong toàn bộ hệ thống chỉ số đánh giá $\mathrm{U}$ theo từng nhóm chủ đề $\mathrm{U}_{\mathrm{i}}$ là: $\mathrm{R}=\left(\mathrm{B}_{1}, \mathrm{~B}_{2}, . . \mathrm{B}_{6}\right)$

Các vector đánh giá toàn diện trong hệ thống chỉ số cấp bậc $\mathrm{U}_{\mathrm{i}}$ là:

$$
\mathrm{B}=\mathrm{A} * \mathrm{R}=\left(\mathrm{b}_{1}, \mathrm{~b}_{2}, \ldots, \mathrm{b}_{\mathrm{m}}\right) .
$$

Kết quả đánh giá sau cùng là: $\mathrm{T}=\mathrm{V} * \mathrm{~B}^{-1}$

\section{Xây dụng ma trận các yếu tố tham gia đánh giá:}

Áp dụng Bảng chỉ thị đánh giá tính bền vững về môi trường năm 2005 của Hội đồng Phát triển bền vững Liên hiệp quốc (UN/CSD) về tài nguyên, môi trường, sinh thái, thể chế, xã hội; Bộ chỉ thị đánh giá tính bền vững của van de Kerk \& Popovici (2008) [2] và Bộ chỉ thị ban hành kèm theo Chỉ thị số 26/2007/CT-TTg về tình hình thực hiện các chỉ tiêu kế hoạch tài nguyên môi trường và phát triển bền vững của Việt Nam để xây dựng bộ chỉ thị đánh giá tính bền vững huyện Phù Cát. Tiến hành thu thập các số liệu từ Cục thống kê Bình Định [1], Sở Tài nguyên và Môi trường và điều tra, khảo sát thực địa, kết quả thể hiện trong bảng 1 .

\section{KẾT QUẢ NGHIÊN CÚU}

\section{Phân loại các bậc bền vững}

Căn cứ vào các chỉ tiêu, kế hoạch phát triển kinh tế xã hội, các quy chuẩn kỹ thuật quốc gia về môi trường và căn cứ trên tình hình thực tế tại địa phương để xây dựng bảng ma trận các bậc bền vững cho huyện Phù Cát với các giá trị cận biên như bảng 2 sau đây. 
Đánh giá tính bền vững đới bờ ...

Bảng 2. Ma trận các bậc bền vững đánh giá đới bờ cấp huyện

\begin{tabular}{|c|c|c|c|c|c|c|}
\hline \multirow{2}{*}{ STT } & \multirow{2}{*}{ CHİ TH! } & \multirow{2}{*}{ KÝ HIẸU } & \multicolumn{4}{|c|}{ Giá trị cận biên các bậc bền vững } \\
\hline & & & $a_{1}$ & $\mathrm{a}_{2}$ & $a_{3}$ & $a_{4}$ \\
\hline 1 & 1.1. Thu nhập bình quân tháng & KT1.1 & 1.000 & 2.000 & 3.000 & 4.000 \\
\hline 2 & 1.2.Vốn sản xuất kinh doanh & $\mathrm{KT} 1.2$ & 500 & 1.000 & 5.000 & 10.000 \\
\hline 3 & 1.3.Tỉ lệ đầu tư trong GDP & KT1.3 & 25 & 30 & 40 & 45 \\
\hline 4 & 1.4. Gía trị sản xuất công nghiệp & KT1.4 & 100 & 200 & 500 & 1.000 \\
\hline 5 & 1.5. Gía trị sản xuất nông nghiệp & KT1.5 & 50 & 100 & 300 & 500 \\
\hline 6 & 1.6. Sản lượng thủy sản nuôi trồng & KT1.6 & 500 & 1.000 & 2.000 & 3.000 \\
\hline 7 & 1.7. Sản lượng khai thác cá biển & KT1.7 & 5.000 & 10.000 & 30.000 & 50.000 \\
\hline 8 & 2.1. Tỷ lệ xã, phường có bác sỹ & $\mathrm{XH} 2.1$ & 20 & 40 & 60 & 80 \\
\hline 9 & 2.2. Tỷ lệ học sinh tốt nghiệp THPT & $\mathrm{XH} 2.2$ & 60 & 70 & 80 & 90 \\
\hline 10 & 2.3.Mật độ dân số & $\mathrm{XH} 2.3$ & 400 & 350 & 300 & 250 \\
\hline 11 & 2.4. Tỷ lệ gia tăng dân số & $\mathrm{XH} 2.4$ & 8 & 10 & 12 & 14 \\
\hline 12 & 2.5.Tỷ lệ giới tính nữ & $\mathrm{XH} 2.5$ & 51,5 & 51 & 50,5 & 50 \\
\hline 13 & 2.6. Tỷ lệ dân cư ở đô thị & $\mathrm{XH} 2.6$ & 20 & 40 & 60 & 80 \\
\hline 14 & 3.1.Tỷ lệ hộ sử dụng điện & VH3.1 & 85 & 90 & 95 & 100 \\
\hline 15 & 3.2.Tỷ lệ hộ dùng nước sạch & VH3.2 & 20 & 40 & 60 & 80 \\
\hline 16 & 3.3.Số hộ có nhà vệ sinh phù hợp & VH3.3 & 20 & 40 & 60 & 80 \\
\hline 17 & 3.4. Thắng cảnh du lịch & VH3.4 & 2 & 4 & 6 & 8 \\
\hline 18 & 3.5. Số cơ sở lưu trú (khách sạn) & VH3.5 & 20 & 40 & 60 & 80 \\
\hline 19 & 3.6. Số thuê bao điện thoại /100 dân & VH3.6 & 20 & 40 & 60 & 80 \\
\hline 20 & 4.1. COD trong nước mặt & MT4.1 & 20 & 15 & 10 & 5 \\
\hline 21 & 4.2. SS nước ven bờ & MT4.2 & 30 & 21 & 14 & 7 \\
\hline 22 & 4.3. CO trong không khí & MT4.3 & 20 & 15 & 10 & 5 \\
\hline 23 & 4.4. Diện tích rừng ngập mặn & MT4.4 & 20 & 30 & 40 & 50 \\
\hline 24 & 4.5. Diện tích thảm cỏ biển & MT4.5 & 30 & 40 & 50 & 60 \\
\hline 25 & 4.6. Diện tích đầm phá & MT4.6 & 400 & 500 & 600 & 700 \\
\hline 26 & 5.1.Nhiệt độ & KH5.1 & 27,6 & 27,4 & 27,2 & 27 \\
\hline 27 & 5.2. Lượng mưa & $\mathrm{KH} 5.2$ & 1.100 & 1.400 & 1.700 & 2.200 \\
\hline 28 & 5.3.Tần suất bão, Iũ, hạn hán & KH5.3 & 4 & 2 & 1 & 0 \\
\hline 29 & 5.4. Số người chết do thiên tai & $\mathrm{KH} 5.4$ & 6 & 3 & 1 & 0 \\
\hline 30 & 5.5.Nhà cửa bị cuốn trôi, sập & KH5.5 & 20 & 10 & 1 & 0 \\
\hline 31 & 5.6. Thiệt hại về tài sản do thiên tai & KH5.6 & 40 & 30 & 20 & 10 \\
\hline 32 & 6.1. Thu gom chất thải rắn sinh hoạt & CS6.1 & 70 & 80 & 90 & 100 \\
\hline 33 & 6.2. Nghiên cứu hệ sinh thái biển & CS6.2 & 2 & 3 & 4 & 5 \\
\hline 34 & 6.3. Diện tích rừng trồng & CS6.3 & 200 & 400 & 600 & 800 \\
\hline 35 & 6.4. Kinh phí sự nghiệp môi trường & CS6.4 & 500 & 1.000 & 1.500 & 2.000 \\
\hline 36 & 6.5. Vốn đầu tư của ngành thủy sản & CS6.5 & 1 & 2 & 3 & 4 \\
\hline 37 & 6.6. Số dự án ứng phó BĐKH & CS6.6 & 2 & 2,5 & 3 & 4 \\
\hline 38 & 6.7.Hỗ trợ vốn ngư dân & CS6.7 & 5 & 10 & 15 & 20 \\
\hline
\end{tabular}

Tính toán ma trận các yếu tố tham gia đánh giá theo thuật toán mờ

Để có ma trận kết quả đánh giá $\mathrm{Ri}=(\mathrm{R} 1$, $\mathrm{R} 2, \ldots \mathrm{R} 6)$ ta áp dụng bảng tra hàm thành viên (membership function) để tính toán khi số liệu ở ma trận U (số liệu) so với ma trận tiêu chuẩn đánh giá $\mathrm{V}$ (bậc bền vững). Bảng này được chia thành 5 cấp, cụ thể như sau:

Bảng 3. Các hàm thuộc cho mô hình đánh giá ma trận $\mathrm{R}_{\mathrm{i}}$

\begin{tabular}{|c|c|c|c|c|c|}
\hline \multirow{2}{*}{$C_{i}$} & \multicolumn{5}{|c|}{ Múcc độ PTBV theo hàm thành viên $f_{j}\left(C_{i}\right)$} \\
\hline & $I$ & II & III & IV & $\boldsymbol{V}$ \\
\hline$c_{i} \leq a_{1}$ & 1 & 0 & 0 & 0 & 0 \\
\hline$a_{1}<c_{i} \leq a_{2}$ & $\frac{a_{2}-c_{i}}{a_{2}-a_{1}}$ & $\frac{c_{i}-a_{1}}{a_{2}-a_{1}}$ & 0 & 0 & 0 \\
\hline $\mathrm{a}_{2}<\mathrm{c}_{\mathrm{i}} \leq \mathrm{a}_{3}$ & 0 & $\frac{a_{3}-c_{i}}{a_{3}-a_{2}}$ & $\frac{c_{i}-a_{2}}{a_{3}-a_{2}}$ & 0 & 0 \\
\hline$a_{3}<c_{i} \leq a_{4}$ & 0 & 0 & $\frac{a_{4}-c_{i}}{a_{4}-a_{3}}$ & $\frac{c_{i}-a_{3}}{a_{4}-a_{3}}$ & 0 \\
\hline$c_{i}>a_{4}$ & 0 & 0 & 0 & 0 & 1 \\
\hline
\end{tabular}


Trong đó $\mathrm{c}_{\mathrm{i}}$ là số liệu của chỉ thị đánh giá, $\mathrm{a}_{1}, \mathrm{a}_{2}, \mathrm{a}_{3}, \mathrm{a}_{4}$ là các cận biên của các tiêu chuẩn đánh giá của các bậc: không bền vững,

$$
\begin{aligned}
R_{1} & =\left[\begin{array}{lllll}
0,00 & 0,00 & 0,71 & 0,29 & 0,00 \\
0,32 & 0,68 & 0,00 & 0,00 & 0,00 \\
0,00 & 0,21 & 0,79 & 0,00 & 0,00 \\
0,02 & 0,98 & 0,00 & 0,00 & 0,00 \\
0,00 & 0,00 & 0,20 & 0,80 & 0,00 \\
1,00 & 0,00 & 0,00 & 0,00 & 0,00 \\
0,00 & 0,56 & 0,44 & 0,00 & 0,00
\end{array}\right] \\
\mathrm{R}_{3} & =\left[\begin{array}{lllll}
0,00 & 0,00 & 0,12 & 0,88 & 0,00 \\
0,00 & 0,30 & 0,70 & 0,00 & 0,00 \\
0,28 & 0,73 & 0,00 & 0,00 & 0,00 \\
1,00 & 0,00 & 0,00 & 0,00 & 0,00 \\
1,00 & 0,00 & 0,00 & 0,00 & 0,00 \\
0,00 & 0,00 & 0,20 & 0,80 & 0,00
\end{array}\right] \\
\mathrm{R}_{5} & =\left[\begin{array}{lllll}
0,00 & 0,00 & 1,00 & 0,00 & 0,00 \\
0,00 & 0,00 & 0,00 & 0,00 & 1,00 \\
0,50 & 0,50 & 0,00 & 0,00 & 0,00 \\
0,00 & 0,00 & 0,50 & 0,50 & 0,00 \\
0,00 & 0,44 & 0,56 & 0,00 & 0,00 \\
1,00 & 0,00 & 0,00 & 0,00 & 0,00
\end{array}\right]
\end{aligned}
$$

Xác định trọng số cho các yếu tố tham gia đánh giá theo phương pháp phân tích tiến trình thứ bậc

Áp dụng phương pháp phân tích trọng số theo tiến trình thứ bậc (AHP) cho từng chủ đề và từng yếu tố (chỉ thị) tham gia đánh giá ta có kết quả về trọng số đánh giá tính bền vững đới bờ huyện Phù Cát như sau:

Trọng số chủ đề:

$A=\left(\begin{array}{llllll}0,08 & 0,18 & 0,20 & 0,23 & 0,14 & 0,18\end{array}\right)$.

Trọng số các chỉ thị:

$A_{1}=\left(\begin{array}{lllllll}0,12 & 0,10 & 0,29 & 0,08 & 0,05 & 0,13 & 0,24\end{array}\right)$

$\mathrm{A}_{2}=\left(\begin{array}{llllll}0,12 & 0,06 & 0,18 & 0,15 & 0,18 & 0,31\end{array}\right)$ ít bền vững, bền vững trung bình, khá bền vững, bền vững.

Kết quả tính toán:

$$
\mathrm{R}_{2}=\left[\begin{array}{ccccc}
0,00 & 0,00 & 0,00 & 0,00 & 1,00 \\
0,00 & 0,00 & 0,00 & 0,00 & 1,00 \\
0,00 & 0,00 & 0,54 & 0,46 & 0,00 \\
0,45 & 0,55 & 0,00 & 0,00 & 0,00 \\
0,20 & 0,80 & 0,00 & 0,00 & 0,00 \\
1,00 & 0,00 & 0,00 & 0,00 & 0,00
\end{array}\right]
$$$$
\mathbf{R}_{4}=\left[\begin{array}{lllll}
0,20 & 0,80 & 0,00 & 0,00 & 0,00 \\
0,00 & 0,00 & 0,00 & 0,00 & 1,00 \\
0,00 & 0,00 & 0,00 & 0,00 & 1,00 \\
0,00 & 0,00 & 0,00 & 0,00 & 1,00 \\
0,00 & 0,00 & 0,00 & 0,40 & 0,60 \\
0,00 & 0,00 & 0,00 & 0,00 & 1,00
\end{array}\right]
$$$$
\mathrm{R}_{6}=\left[\begin{array}{ccccc}
1,00 & 0,00 & 0,00 & 0,00 & 0,00 \\
1,00 & 0,00 & 0,00 & 0,00 & 0,00 \\
0,00 & 0,66 & 0,35 & 0,00 & 0,00 \\
0,00 & 0,00 & 0,20 & 0,80 & 0,00 \\
0,00 & 0,00 & 1,00 & 0,00 & 0,00 \\
1,00 & 0,00 & 0,00 & 0,00 & 0,00 \\
1,00 & 0,00 & 0,00 & 0,00 & 0,00
\end{array}\right]
$$

$$
\begin{aligned}
& A_{3}=\left(\begin{array}{llllll}
0,19 & 0,19 & 0,07 & 0,19 & 0,20 & 0,16
\end{array}\right) \\
& A_{4}=\left(\begin{array}{llllll}
0,11 & 0,06 & 0,18 & 0,13 & 0,22 & 0,31
\end{array}\right) \\
& A_{5}=\left(\begin{array}{llllll}
0,09 & 0,13 & 0,20 & 0,19 & 0,14 & 0,25
\end{array}\right) \\
& A_{6}=\left(\begin{array}{lllllll}
0,10 & 0,16 & 0,15 & 0,20 & 0,13 & 0,15 & 0,11
\end{array}\right)
\end{aligned}
$$

Sau khi có ma trận kết quả đánh giá $\mathrm{R}_{\mathrm{i}}$ các chỉ thị theo hàm thành viên ta nhân với trọng số của từng chỉ thị $A_{i}=\left(A_{1}, A_{2}, \ldots A_{6}\right)$ ta có ma trận kết quả đánh giá $\mathrm{B}_{\mathrm{i}}=\mathrm{A}_{\mathrm{i}} * \mathrm{R}_{\mathrm{i}}$. Trong đó $\mathrm{B}_{\mathrm{i}}$ $=\left(\mathrm{B}_{1}, \mathrm{~B}_{2}, \ldots \mathrm{B}_{6}\right)$.

Ma trận đánh giá toàn diện mờ trong toàn bộ hệ thống U là R: 


$$
\mathrm{R}=\left[\begin{array}{c}
\mathrm{B}_{1} \\
\mathrm{~B}_{1} \\
\cdot \\
\cdot \\
\cdot \\
\mathrm{B}_{\mathrm{s}}
\end{array}\right]=\left[\begin{array}{cccc}
\mathrm{b}_{11} & \mathrm{~b}_{12} & \ldots & \mathrm{b}_{1 \mathrm{~m}} \\
\mathrm{~b}_{21} & \mathrm{~b}_{22} & \ldots & \mathrm{b}_{2 \mathrm{~m}} \\
\cdot & \cdot & \ldots & \cdot \\
\cdot & \cdot & \ldots & \cdot \\
\cdot & . & \ldots & \cdot \\
\mathrm{b}_{\mathrm{s} 1} & \mathrm{~b}_{\mathrm{s} 2} & \ldots & \mathrm{b}_{\mathrm{sm}}
\end{array}\right]=\left[\begin{array}{ccccc}
0,159 & 0,344 & 0,426 & 0,071 & 0,000 \\
0,413 & 0,227 & 0,099 & 0,084 & 0,177 \\
0,411 & 0,111 & 0,187 & 0,291 & 0,000 \\
0,021 & 0,085 & 0,000 & 0,087 & 0,807 \\
0,348 & 0,163 & 0,262 & 0,097 & 0,129 \\
0,516 & 0,101 & 0,227 & 0,156 & 0,000
\end{array}\right]
$$

Vectơ đánh giá mờ toàn diện huyện Phù Cát: $\mathrm{B}=\mathrm{A} * \mathrm{R}$

$$
\begin{aligned}
B=\left(\begin{array}{llllll}
0,08 & 0,18 & 0,20 & 0,23 & 0,14 & 0,18
\end{array}\right) *\left[\begin{array}{llllll}
0,159 & 0,344 & 0,426 & 0,071 & 0,000 \\
0,413 & 0,227 & 0,099 & 0,084 & 0,177 \\
0,411 & 0,111 & 0,187 & 0,291 & 0,000 \\
0,021 & 0,085 & 0,000 & 0,087 & 0,807 \\
0,348 & 0,163 & 0,262 & 0,097 & 0,129 \\
0,516 & 0,101 & 0,227 & 0,156 & 0,000
\end{array}\right] \\
B=A * R=\left[\begin{array}{lllllll}
b 1 & b 2 & b 3 & b 4 & b 5
\end{array}\right]=\left[\begin{array}{llllll}
0,312 & 0,150 & 0,164 & 0,139 & 0,236
\end{array}\right]
\end{aligned}
$$

Kết quả đánh giá: $\mathrm{T}=\mathrm{V} * \mathrm{~B}^{-1}=\left[\begin{array}{lllll}1 & 2 & 3 & 4 & 5\end{array}\right] *\left[\begin{array}{c}0,312 \\ 0,150 \\ 0,164 \\ 0,139 \\ 0,236\end{array}\right]=\mathbf{2 , 8 4}$

Với 5 giá trị phân bậc 1, 2, 3, 4, 5 ta chia đều 5 khoảng, nếu điểm đánh giá:

[1-1,8] huyện Phù Cát thuộc loại không bền vững.

[1,8-2,6] huyện Phù Cát thuộc loại kém bền vững.

[2,6-3,4] huyện Phù Cát thuộc loại bền vững trung bình.

[3,4-4,2] huyện Phù Cát thuộc loại khá bền vững. vững.

[4,2-5] huyện Phù Cát thuộc loại bền

Kết quả đánh giá toàn diện dựa trên thuật toán mờ về mức độ phát triển bền vững huyện Phù Cát là 2,84 nằm trong khoảng $[\mathbf{2 , 6 - 3 , 4 ]}$ thuộc bậc bền vững trung bình (bậc $\mathrm{v}_{3}$ ).

\section{KẾT LUẬN}

Trong nghiên cứu này, các chỉ số đánh giá là những yếu tố ảnh hưởng quan trọng nhất. Tác giả đã chọn lọc và thiết lập bộ chỉ thị để đánh giá tính bền vững phù hợp với tình hình thực tế với 6 nhóm chủ đề và 38 chỉ thị với các bậc bền vững (5 bậc) cho huyện Phù Cát.

Áp dụng phương pháp đánh giá dựa theo thuật toán lý thuyết mờ (FCE) kết hợp với phương pháp xác định trọng số theo tiến trình phân tích thứ bậc (AHP), kết quả đánh giá tổng thể cho thấy huyện Phù Cát có tính bền vững ở mức trung bình.

Thông qua áp dụng phương pháp đánh giá toàn diện dựa trên thuật toán mờ trong đó kết hợp xác định trọng số các chỉ thị bằng kỹ thuật phân tích tiến trình thứ bậc có thể nói đây là những phương pháp đánh giá định lượng và 
tiên tiến nhằm lượng hóa mức độ bền vững của huyện Phù Cát.

Ngoài ra, kết quả đánh giá có thể sử dụng tham khảo trong công tác quy hoạch, xây dựng kế hoạch phát triển kinh tê-xã hội cho các địa phương khu vực đới bờ ở cấp huyện đối với khu vực ven biển miền Trung.

Nhằm khai thác, sử dụng hợp lý nguồn tài nguyên, bảo vệ môi trường và phát triển bền vững huyện Phù Cát trong thời gian tới địa phương cần thực hiện những nghiên cứu, đánh giá cụ thể hiệu quả của hoạt động khai thác, sử dụng tài nguyên và quy hoạch phát triển kinh tế-xã hội gẳn với kế hoạch hành động ứng phó với biến đồi khí hậu.

\section{TÀI LIẸU THAM KHẢO}

1. Cuc Thống kê Bình Định, 2012. Niên giám thống kê 2012. Nxb. Thống kê, 285 tr.
2. Kerk, G. V., Popovici, C., 2008. The Sustainable Society Index - SSI, a novel tool for measuring progress towards sustainability. Conference on Measuring and Fostering the Progress of Societies, Moscow, pp. 1-7.

3. Saaty, T. L., 2000. Models, Methods, Concepts \& Applications of the Analytic Hierarchy Process, Boston: Kluwer Academic Publishers, pp. 9-26.

4. Sun, J., Yong, W., Youzhi, H., Zhen, D., 2006. Fuzzy Comprehensive Evaluation Model and Influence Factors Analysis on Comprehensive Performance of Green Buildings. Journal of Renewable Energy Resources and a Greener Future, Vol.VIII4-2, ICEBO, Shenzhen, China, pp. 6-11.

\title{
SUSTAINABILITY ASSESSMENT OF COASTAL ZONE - A PILOT IN PHU CAT DISTRICT, BINH DINH PROVINCE
}

\author{
Vo Thanh Tinh ${ }^{1}$, Che Dinh Ly ${ }^{1}$, Luong Van Thanh ${ }^{2}$ \\ ${ }^{1}$ Institute for Environment and Resources, Vietnam National University at Ho Chi Minh City \\ ${ }^{2}$ Institute of Coastal and Offshore Engineering-Vietnam Academy for Water Resources
}

\begin{abstract}
Based on the sustainability assessment indicators conducted previously, the authors studied and built the sustainable indicators for the factors involved in the assessment with 6 themes and 38 indicators as well as sustainable levels (5 levels) in order to assess the sustainable conditions in coastal zone at the pilot site in Phu Cat district. The authors also proposed to apply the method of analysis hierarchy process (AHP) to establish a set of weights for each subject and indicator. After calculating the assessment results for each indicator through the method of fuzzy comprehensive evaluation (FCE) by the membership functions, the overall evaluation results for the entire Phu Cat district were done. Through the implementation of these methods the evaluation results showed that the sustainability of Phu Cat district is at average level.
\end{abstract}

Keyword: Sustainability, coastal zone, Phu Cat district. 